\title{
Pelatihan Dasar Mikrokontroler Kelistrikan Bagi Siswa Mas Annida Al Islamy
}

\author{
Efy Yosrita $^{1}$; Indrianto ${ }^{2}$; Darma Rusjdi ${ }^{3}$; Meilia Nur Indah Susanti ${ }^{4}$; \\ Dewi Arianti Wulandari ${ }^{5}$; Rizqia Cahyaningtyas ${ }^{6}$; Herman Bedi Agtriadi ${ }^{7}$
}

\author{
1, 2, 3, 4, 5, 6, 7 Sekolah Tinggi Teknik PLN, Departemen Informatika \\ ${ }^{1}$ efy.yosrita@sttpln.ac.id
}

\begin{abstract}
The activity of Pengabdian Kepada Masyarakat STT-PLN team is to organize the Basic Electrical Microcontroller Training for Annida Al Islamy Private Aliyah High School Students. This training aims to support the students to gain additional skills that are not provided in the school curriculum, but are needed for increasing the students' knowledge and skill regarding Embedded Systems, especially electricity. In this training, students learn about embedded system theoretically and practically using the Amorek practice module. It is a practice module which consists of several activities. The training was held for 2 days, where the material on the first day was an introduction to general theory about embedded systems and the Amorek module. The second day's training material was practice on the Embedded System using the Amorek module. The number of participants who joined in the training were 15 students in grade 10 and grade 11 with 9 male students and 6 female students. During the Embedded System practices using the Amorek module, participants were divided into five groups each consisting of 3 (three) participants. The last days of the activity an evaluation of the results of observations and questionnaires to all students was carried out. The entire implementation process is carried out in the computer laboratory room. Based on the questionnaires and field observations, students were able to complete the practicum material provided during the training and the school expected the continuity of this PKM activity at Annida Al Islamy Private Aliyah Middle School.
\end{abstract}

Keywords: PKM, mikro kontroler, MOREK, MAS Annida Al Islamy

\begin{abstract}
ABSTRAK
Kegiatan Pengabdian kepada masyarakat STT-PLN berupa Pelatihan Dasar Mikrokontroler Kelistrikan bagi Siswa Sekolah Menengah Aliyah Swasta Annida Al Islamy. Pelatihan ini bertujuan agar siswa mendapatkan ketrampilan tambahan yang tidak didapatkan pada kurikulum sekolah namun cukup diperlukan untuk meningkatkan wawasan pengetahuan dan ketrampilan mengenai Embedded system khususnya mikrokontroler. Dalam pelatihan ini siswa diajarkan mengenai teori dan praktek mengenai Embedded system menggunakan modul praktek MOREK. MOREK merupakan modul praktikum yang terdiri dari beberapa praktikum. Pelatihan diadakan selama 2 hari, dimana materi hari pertama adalah pengantar teori umum mengenai Embedded system dan pengenalan MOREK. Materi pelatihan hari kedua yakni praktek mengenai Embedded system menggunakan modul MOREK. Jumlah peserta yang mengikuti pelatihan sebanyak 15 orang siswa kelas 10 dan kelas 11 dengan jumlah siswa pria 9 orang dan siswa wanita 6 orang. Pada saat praktek pelaksanaan modul, peserta dibagi menjadi lima kelompok masing-masing terdiri dari 3 (tiga) peserta. di akhir kegiatan dilakukan evaluasi dari hasil pengamatan dan kuesioner kepada seluruh siswa. Seluruh proses pelaksanaan dilakukan di ruang laboratorium komputer. Berdasarkan kuisioner dan pengamatan dilapangan siswa mampu menyelesaikan dengan baik materi praktikum yang di berikan selama pelatihan serta pihak sekolah mengharapkan kontinuitas dari kegiatan PKM ini di Sekolah Menengah Aliyah Swasta Annida Al Islamy.
\end{abstract}

Kata Kunci: PKM, mikro kontroler, MOREK, MAS Annida Al Islamy 


\section{PENDAHULUAN}

Kegiatan Tridarma Perguruan Tinggi yang harus dilaksanakan oleh setiap Dosen salah satunya melakukan kegiatan pengabdian kepada masyarakat (PKM) pada setiap semester. Dalam penyelenggaraan kegiatan PKM, tim mengacu kepada keubutuhab masyarakat yang menjadi mitra PKM. Masyarakat yang menjadi target kegiatan dapat berasal dari berbagai kalangan. Pada PKM periode Tahun Akademik semester Genap 2018-2019, mitra masyarakat yang bekerjasama melaksanakan Program Kemitraan Masyarakat (PKM) dengan Jurusan Teknik Informatika adalah MAS Annida Al Islamy. Berdasarkan survey dan wawancara awal dengan Kepala Sekolah MAS Annida Al Islamy, Diperoleh informasi bahwa pada kurikulum Pendidikan MAS Annida Al Islamy, tidak terdapat mata pelajaran yang membahas mengenai Embeeded System dan pihak Sekolah mengajukan usulan agar dilaksanakan pelatihan bagi siswa kelas 10 dan 11 mengenai Embedded System, mikrokontroler dan pemanfaatan dalam kehidupan sehari - hari. Berdasarkan hal tersebut, maka untuk pelaksanaan kegiatan PKM, menyelenggarakan pelatihan selama dua hari mengenai pengenalan mikro kontroler dan pemanfaatannya. Tujuan pelaksanaan PKM adalah mengenalkan dan mesosisalisasikan pemanfaatan mikrokontroler dalam kehidupan sehari-hari sehingga diharapkan siswa mampu merakit dan membuat alat dengan menggunakan mikrokontroller.

Beberapa teori yang menjadi materi pada pelatihan diantaranya :

a. Embedded System merupakan sebuah system yang dibuat untuk suatu kebutuhan khusus [1].

b. Mikrokontroler sebuah system komputer yang seluruh atau sebagian besar elemennya dikemas dalam satu chip IC, sehingga sering disebut single chip microcomputer [2]

c. Morek merupakan modul praktikum Embedded System yang di laksanakan di program Studi Teknik Informatika[3]

\section{METODE}

Metode pelaksanaan yang digunakan untuk melaksanakan kegiatan Program Kemitraan Masyarakat (PKM) tahun 2018/2019 Semester Ganjil ini sebagai berikut:

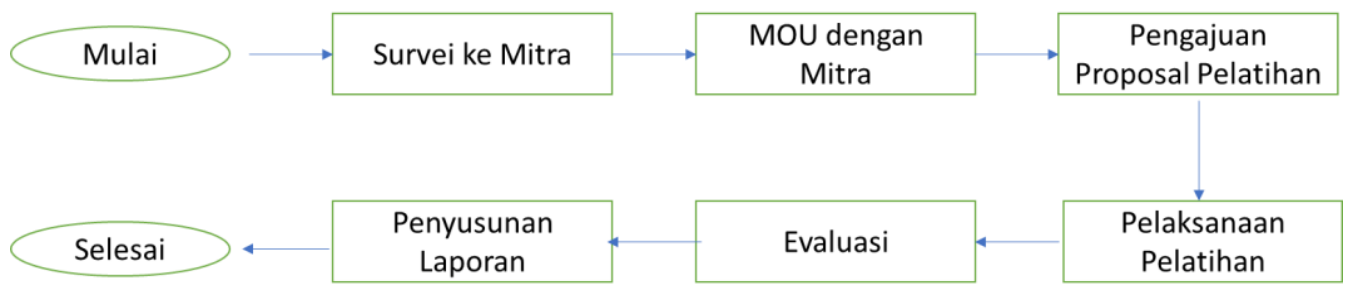

Gambar 1. Tahapan Pelaksanaan Kegiatan PKM

Kegiatan PKM ini, terbagi menjadi 6 kegiatan, diantaranya :

1. Survei ke mitra, hal ini dilakukan oleh tim untuk mengetahui permasalahan yang di hadapi oleh mitra dan solusi yang bisa diajukan oleh tim PKM untuk menyelesaikan masalah tersebut.

2. MOU dengan mitra, setelah disepakati kegiatan yang akan dilaksakan, kemudian di buatkan MOU yang ditanda tangani pihak sekolah MAS Annida Al Islamy dan pihak STT-PLN.

3. Pengajuan Proposal, tim PKM mnyusun proposal dengan judul PELATIHAN DASAR MIKROKONTROLER KELISTRIKAN BAGI SISWA MAS ANNIDA AL ISLAMY yang diajukan kepada MAS Annida Al Islamy dan ke LPPM 
4. Pelaksanaan Pelatihan, dilaksanakan selama 2 pertemuan, yakni tamggal 8 Maret 2019 dan 22 Maret 2019, sesuai dengan ketersedian waktu pihak sekolah

Pelaksanaan Pengbadian pada Masyarakat pada semester ini dilaksanakan pada tanggal 8 dan 22 Maret 2019 semester ganjil tahun akademik 2018/2019 di Laboratorium Komputer MAS Annida Al Islamy, dimana tim P2M terdiri atas dosen-dosen jurusan Teknik Informatika.Pelaksanaan P2M

5. Evaluasi, dilakukan meleui pengisian kuisioner oleh siswa peserta dingan tipe kusioner jawaban tertutup

6. Penyusunan Laporan, tim melaporkan seluruh rangkaian kegiatan dalam bentuk laporan tertulis, yang diserahkan kepada LPPM STT-PLN.

\section{HASIL dan PEMBAHASAN}

Hasil pelaksanaan kegiatan PKM yakni, terselenggaranya pelatihan dengan judul PELATIHAN DASAR MIKROKONTROLER KELISTRIKAN BAGI SISWA MAS ANNIDA AL ISLAMY. Dengan lokasi kegiatan di MAS Annida Al Islamy berlokasi di Jl. Raya Duri Kosambi No.33A, RT.4/RW.7, Duri Kosambi, Cengkareng, Kota Jakarta Barat, Daerah Khusus Ibukota Jakarta 11750, Indonesia. Pelatihan dilaksanakan dalam 2 hari, tanggal 8 dan 22 Maret 2019. Pada pelaksanaan tanggal 8 maret 2019 tim memberikan penjelasan tentang Modul Rangkaian Embeded dan Kelistrikan. rangkaian mikrokontroller secara sederhana dengan alat-alat atau kontrol yang digunakan selama pelatihan Pada Tanggal 22 Maret 2019 dilaksanakan praktek Kontrol Lampu Listrik AC Dengan Relay Pada Arduino Menggunakan Modul Bluetooth Dan Android. Peserta pada kegiatan ini adalah siswa-siswa MAS Annida Al Islamy. Jumlah peserta pada Hari 1: Jumat, 8 Maret 2019 berjumlah: 12 siswa dan Hari 2: Jumat, 22 Maret 2019 berjumlah: 9 siswa. Pada kegiatan pengabdian ini tim membuat pretest dan posttest untuk mengetahui pemahaman mengenai Embedded system di tingkat sekolah menengah atas, dengan hasilnya sebagai berikut

Pada pertemuan pertama dilaksanakan pretest dari 12 siswa yang akan melaksanakan pelatihan Rangkaian Embeded dan kelistrikan sejumlah 5 pertanyaan dengan jawaban tertutup. Dari hasil Pretest diambil kesimpulan bahwa siswa tertarik untuk mempelajari pengetahuan tentang komputer disekolah, baik tentang perkembangan teknologi, komponen-komponen komputer sampai dengan aplikasi-aplikasi komputer. Namun siswa kurang memahami tentang kebutuhan akan media pembelajaran yang berkaitan tentang Embedded system karena siswa belum mengetahui dan mempelajari tentang Embedded system dan rangkaian listrik. Pada pertemuan Kedua tgl 22 Maret 2019 dilaksanakan posttest dari 9 siswa yang melaksanakan praktek Rangkaian Embeded dan kelistrikan, sejumlah 5 pertanyaan, dengan jaaban tertutp. Dari hasil Posttest diperoleh kesimpulan bahwa siswa masih belum ngetahui dengan baik mengenai Embedded system dan rangkaian listrik mulai dari pengetahuan alat-alat yang dibutuhkan dalam mempelajari Embedded system serta merangkai Embedded system. Berikut hasil Pretest dan Postest yang dilakukakn ditampilkan pada tabel 1.

Tabel 1. presentase hasil evaluasi

\begin{tabular}{|l|l|l|l|}
\hline No & Pertanyaan & Pre-Test & Post Test \\
\cline { 3 - 4 } & & \\
\hline 1 & Apakah menurut anda pengetahuan & $5(11) 91,67 \%$ & $5(7) 77,78 \%$ \\
& tentang komputer sangat penting & $4(1) \quad 8,33 \%$ & $4(1) 11,11 \%$ \\
& diketahui oleh anak-anak mulai & $3(0)$ & $3(1) 11,11 \%$ \\
& usia sekolah? & $2(0)$ & $2(0)$ \\
\hline
\end{tabular}




\begin{tabular}{|c|c|c|c|}
\hline & & $1(0)$ & $1(0)$ \\
\hline 2 & $\begin{array}{l}\text { Kemajuan teknologi dibidang } \\
\text { computer harus diikuti dengan } \\
\text { pemberian materi yang diberkaitan } \\
\text { tentang computer baik tentang } \\
\text { komponen-komponen computer } \\
\text { maupun aplikasi-aplikasinya } \\
\text { disekolah? }\end{array}$ & $\begin{array}{l}5(8) 66,67 \% \\
4(4) 33,33 \% \\
3(0) \\
2(0) \\
1(0)\end{array}$ & $\begin{array}{l}5(7) 77,78 \% \\
4(2) 22,22 \% \\
3() \\
2(0) \\
1(0)\end{array}$ \\
\hline 3 & $\begin{array}{l}\text { Apakah anda setuju jika ada suatu } \\
\text { alat atau media yang dapat } \\
\text { digunakan untuk memudahkan } \\
\text { mempelajari suatu system } \\
\text { computer? }\end{array}$ & $\begin{array}{l}5(8) 66,67 \% \\
4(3) 25,00 \% \\
3(1) \quad 8,33 \% \\
2(0) \\
1(0)\end{array}$ & $\begin{array}{l}5(6) 66,67 \% \\
4(3) 33,33 \% \\
3(0) \\
2(0) \\
1(0)\end{array}$ \\
\hline 4 & $\begin{array}{l}\text { Apakah anda setuju jika aplikasi } \\
\text { Embedded system ini dapat } \\
\text { membantu dalam memahami } \\
\text { pembahasan tentang system } \\
\text { computer? }\end{array}$ & $\begin{array}{l}5(5) 41,67 \% \\
4(5) 41,67 \% \\
3(2) 16,67 \% \\
2(0) \\
1(0)\end{array}$ & $\begin{array}{l}5(5) 55,56 \% \\
4(4) 44,44 \% \\
3(1) \\
2(0) \\
1(0)\end{array}$ \\
\hline 5 & $\begin{array}{l}\text { Apakah anda setuju jika aplikasi } \\
\text { Embedded system ini diajarkan } \\
\text { kepada siswa-siswa sekolah? }\end{array}$ & $\begin{array}{l}5(7) 58,33 \% \\
4(5) 41,67 \% \\
3(0) \\
2(0) \\
1(0)\end{array}$ & $\begin{array}{l}5(7) 77,78 \% \\
4(2) 22,22 \% \\
3(0) \\
2(0) \\
1(0)\end{array}$ \\
\hline
\end{tabular}

\section{KESIMPULAN dan SARAN}

Dari hasil pelaksanaan P2M yang telah dilaksanakan terdapat beberapa kendala yang dihadapi yaitu kegiatan pelaksanaan P2M dilaksanakan pada waktu yang singkat sehingga siswa tidak terlalu menguasai dengan materi yang diberikan, diharapkan kegiatan pelatihan ini dapat dilanjutkan dengan waktu yang sesuai dengan target materi yang diberikan, agar dapat menumbuhkan minat siswa-siswa untuk memahami tentang Embedded system dan membuat rangkaian listik dan mikrokontroller dapat berjalan dengan baik.

Mengacu pada rencana strategis Jurusan Teknik Informatika khususnya dalam penerapan dan pengembangan Modul Embeded system dan rangkaian listrik, maka rencana kegiatan berikutnya dari pengembangan tersebut adalah berupa kegiatan : implementasi dari modul-modul Embedded system dan rangkaian listrik yang telah dibuat dari hasil hibah penelitian terapan yang dapat dimanfaatkan oleh masyarakat. Dan diharapkan dari kegiatan Pengabdian pada masyarakat ini dapat dikembangkan sesuai kebutuhan masyarakat, sehingga dibutuhkan waktu yang cukup dalam program ini.

\section{UCAPAN TERIMA KASIH}

Kepada pihak yang membantu pelaksanaan kegiatan ini berjalan denganlancar yaitu kepada pimpinan Sekolah Menengah Aliyyah Annida Al Islamy, Jakarta Barat dan Pimpinan STT-PLN melalui LPPM STT-PLN 


\section{DAFTAR PUSTAKA}

[1] S. Rifka, F. Firdaus, and W. F. Ramadhan, "Penerapan Embedded System pada Sistem Pintar Pengendali Multi Perangkat dalam Kelas berbasis Intel Galileo dan Web," J. Rekayasa Elektr., vol. 14, no. 1, pp. 51-61, 2018.

[2] A. N. N. Chamim, "Penggunaan Microcontroller Sebagai Pendeteksi Posisi Dengan Menggunakan Sinyal Gsm," J. Inform., vol. 4, no. 1, pp. 430-439, 2010.

[3] Indrianto; and M. N. I. Susanti, buku morek barul. 2018. 